\title{
Neutron Diffraction Investigation of Residual Stresses in Nickel Based Austenitic Weldments on Creep Resistant Cr-Mo-V Material
}

\author{
P. Doubell ${ }^{\dagger 1, a^{*}}$, M. Newby ${ }^{1, b}$, D. Hattingh ${ }^{2, c}$, A. Steuwer ${ }^{2,3, d}$ and M.N. James ${ }^{2,4, e}$ \\ ${ }^{1}$ Eskom Holdings SOC Ltd, Lower Germiston Road, Rosherville, Johannesburg, South Africa \\ ${ }^{2}$ Nelson Mandela Metropolitan University Port Elizabeth, South Africa \\ ${ }^{3}$ University of Malta, Msida MSD 2080, Malta \\ ${ }^{4}$ University of Plymouth, Drake Circus, Plymouth, UK

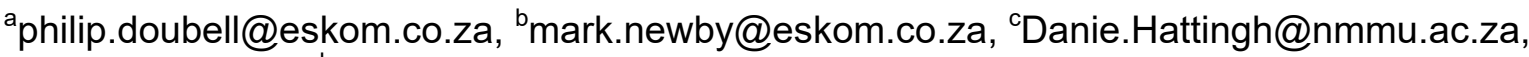 \\ daxel.steuwer@gmail.com, ${ }^{\mathrm{e}} \mathrm{m} . j \mathrm{~m}$ es@plymouth.ac.uk
}

\section{Keywords: Creep Resistant Alloy, Butt Weld, Stress Relief Crack, Residual Stress, Post-Weld Heat Treatment, Neutron Diffraction Strain Measurement}

\begin{abstract}
Residual creep ductility of service-aged Cr-Mo-V creep resistant material is considerably lower than that of new material; this affects the long-term creep life performance of components manufactured from such alloys as the creep rate in aged alloy is considerably higher than for new materials. This study focused on the effects of residual stress and post-weld heat treatment (PWHT) on the remaining life of creep-exhausted material after repair welding using nickel-based consumables. Residual stresses attributed to the ferrite-to-austenite phase transformations involve a sudden volume change of the weld material. This can adversely affect aged material, e.g. a $1 / 2 \mathrm{Cr}-1 / 2 \mathrm{Mo}-1 / 4 \mathrm{~V}$ alloy, with low creep ductility and known notch sensitivity rendering this alloy prone to reheat cracking. Coupons prepared from creep damaged $\mathrm{Cr}-\mathrm{Mo}-\mathrm{V}$ pipes (323 mm outside diameter and $36 \mathrm{~mm}$ thick) were joined with the tungsten inert gas (TIG) and manual metal arc (MMA) welding processes simulating the original construction joints. Standard welding procedures were used with and without the addition of stress relief and temper post-weld heat treatment. Butt weld coupons were subsequently prepared, using a Ni-based consumable and a conventional ferritic consumable, for tri-axial stress measurements on the SALSA neutron diffraction beamline (ILL Grenoble), $\mathrm{d}_{0}$ calibration used toothcomb specimens sectioned from the weld coupons. The industrial application of the experiments was sensitivity analysis of residual life prediction in FE modelling of plant system stresses in weld-repaired $\mathrm{Cr}$ Mo-V creep resistant materials.
\end{abstract}

\section{Introduction}

The welding of high temperature and pressure components on power plants is considered a wellestablished and mature technology. It is used extensively during construction and maintenance activities. Maintenance activities, however, include welding and the effects of thermal aging of materials and components due to operation under load. These thermal effects can include phenomena such as a reduction in ductility, creep damage and high notch sensitivity that could render a component irreparable.

The chromium-molybdenum-vanadium (Cr-Mo-V) family of creep resistant alloys is known to be susceptible to weld and heat treatment related problems such as reheat cracking [1], also known as stress-relief cracking (SRC). This phenomenon is typified by cracks that occur in the coarse grained heat-affected zone, designated as a Type III crack in the categories proposed by Schüller [2], according to their location and geometry in a weld. Brett [3] subsequently added the 
term Type IIIa crack which better describes the character of this intergranular SRC (See Fig. 1) found in the CGHAZ adjacent to the fusion line.
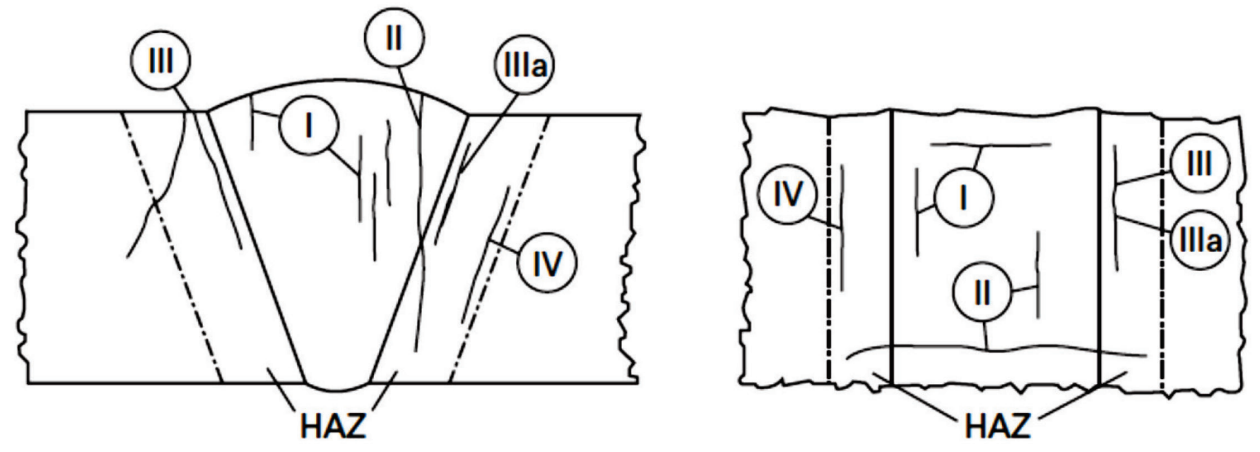

Fig. 1: Type IIIa reheat crack location [2].

SRC may occur when welds are exposed to high temperature during post-weld heat treatment or during operation at high temperature when creep ductility is not adequate to accommodate the elevation of strain due to residual stress [4].

\section{Rationale for the application of Nickel-based weld consumables on ferritic alloys}

Austenitic welding consumables are often proposed for application on ferritic base materials as an effective tool to alleviate the tendencies for reheat cracking and to extend creep life in refurbishment of components and support plant life-extension programmes. Limited information on the topic can be found in published literature on which to base a refurbishment strategy for nickel (Ni)-based alloys, in lieu of a matching ferritic filler material. Some information suggests that welding with Ni-based austenitic weld consumables could be beneficial in reducing weldinduced residual stresses. Nerger et al. reported a refurbishment project at the Hagenwerder Power Station in Germany to repair reheat cracking damage on butt welds joining Grade 14MoV6-3 pipes on the hot reheat pipe network [5]. Attempts to repair with ferritic weld consumables followed by PWHT resulted in extensive new cracking occurring in the CGHAZ. The solution adopted was to perform the weld repairs with a temper-bead technique using Nibased weld consumables without subsequent PWHT. Depositing Ni-base electrodes reduces the off-loading effects arising from matched strength electrodes. Such electrodes create a narrower heat-affected zone (HAZ) than ferritic electrodes of the same size. Another motivation for utilising Ni-based consumables is to achieve a relatively lower stress weld as no phase transformation occurs in the weld metal solid phase due to stability of the austenitic phase from low temperatures up to the melting point.

No phase transformation stresses occur, giving lower thermal stresses during the weld cycle when compared with ferritic consumables where ferrite-to-austenite transformation involves a sudden volume change of the weld material. This can have an adverse effect on aged material with low creep ductility. When the notch sensitivity of an alloy such as Grade 14MoV6-3 is added into the equation, this group of alloys becomes prone to the reheat cracking phenomenon (Fig. 2).

The Ni-base weld metal generally has better toughness than a ferritic weld metal, while the higher solubility of hydrogen in austenitic weld metal is thought to alleviate the risk of hydrogenassisted cracking.

A disadvantage of using nickel-base filler metal is that the dissimilar metal combination considerably hinders any NDE by ultrasonic-testing methods, due to the difference in ultrasonic 
wave-propagation characteristics, while magnetic particle testing cannot be used as a surface crack-detection method. Notwithstanding these issues, the potential benefits for using nickel as a part of a repair strategy purportedly outweigh the disadvantages when applied correctly and supported by sufficient engineering assessment.

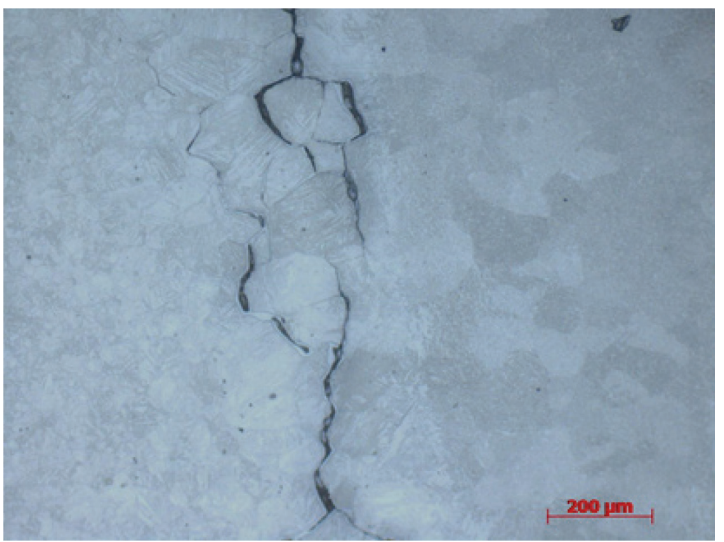

Fig. 2: Reheat cracking damage in weld heat-affected zone.

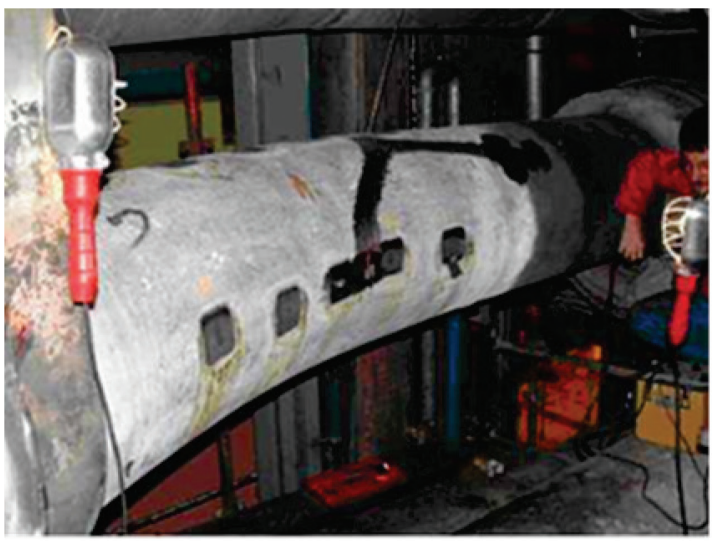

Fig. 3: Surface replication for determining microstructure integrity.

Plant life extension calculations and repairs rely on in-situ evaluation techniques such as surface replication (Fig. 3) to detect the possible incidence of creep damage, hydrogen cracks and $\mathrm{SRC}$, an approach that supports efforts to determine component integrity down to microstructural level. This study investigated some of these claims regarding the virtues of Ni-base weld consumables, in particular the claims of a lower stressed weld condition compared with using ferritic weld consumables that match the base alloy.

\section{Welding of test pieces and mechanical tests}

Due to the relatively wide potential applications of so-called reduced stress welding techniques, it was decided to focus on one particular application often encountered during maintenance activities i.e. spool-piece replacement on the main steam and re-heater pipework, typically manufactured from creep resistant alloys to BS EN 10216-2 Grade 14MoV6-3 which is known for high levels of notch sensitivity. Table 1 lists the nominal chemical constituents for this alloy.

Table 1: Chemical composition for Grade 14MoV6-3 creep resistant alloy

\begin{tabular}{crrrrrrc}
$\mathrm{C}$ & $\mathrm{Cr}$ & $\mathrm{Mo}$ & $\mathrm{V}$ & $\mathrm{Si}$ & $\mathrm{Mn}$ & $\mathrm{P}$ & $\mathrm{S}$ \\
\hline $0.1-0.18$ & $0.3-0.6$ & $0.5-0.7$ & $0.22-0.32$ & $0.1-0.35$ & $0.4-0.7$ & $0.035 \max$ & $0.035 \max$
\end{tabular}

Spool-pieces were prepared from retired creep damaged Cr-Mo-V pipes, nominally $323 \mathrm{~mm}$ outside diameter and $36 \mathrm{~mm}$ thick, joined with the TIG and MMA welding processes. For this study conventional ferritic $2 \frac{1}{4} \% \mathrm{Cr}-1 \%$ Mo weld consumables were used for one coupon while the second coupon used a $70 \% \mathrm{Ni}-19 \% \mathrm{Cr}-5 \% \mathrm{Mn}-2 \% \mathrm{Nb}-1.5 \% \mathrm{Mo}-3 \% \mathrm{Fe}$ type austenitic weld consumable. Standard welding procedures were followed both with, and without, additional stress relief and temper PWHT for comparison.

\section{Residual stress measurement}

The aim of the experiment was to make neutron diffraction residual stress measurements in four test coupons made with either matching ferritic or Ni-based weld consumables to validate the heat-treatment processes (see Table 2). The measurements were performed at the Institut LaueLangevin (ILL) on the Strain Analyser for Large Scale Engineering Applications (SALSA) 
beamline in the five days allocated for experiment 1-02-31. Fig. 4 shows the general layout of the test cubicle with a coupon mounted on the hexapod table. Neutron diffraction is the only technique suitable for measuring residual strains in the thick steel samples used in this experiment. A positional matrix comprising 31 points was originally planned for each sample; however, when the experiment started it was evident that weld texture led to extremely long measurement times and the matrix had to be reduced to three lines for the as-welded samples $(5$, 16 and $35 \mathrm{~mm})$ and one line $(16 \mathrm{~mm})$ for the heat-treated samples as shown in Fig. 5.

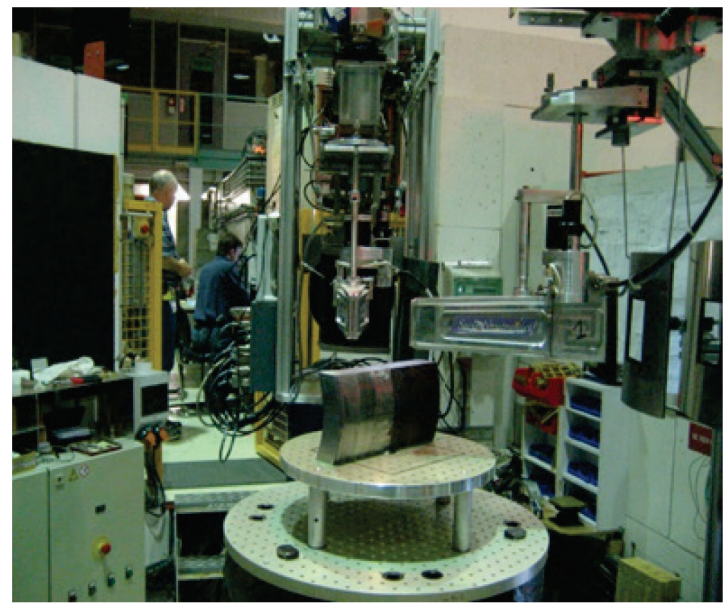

Fig. 4: SALSA test cubicle layout.

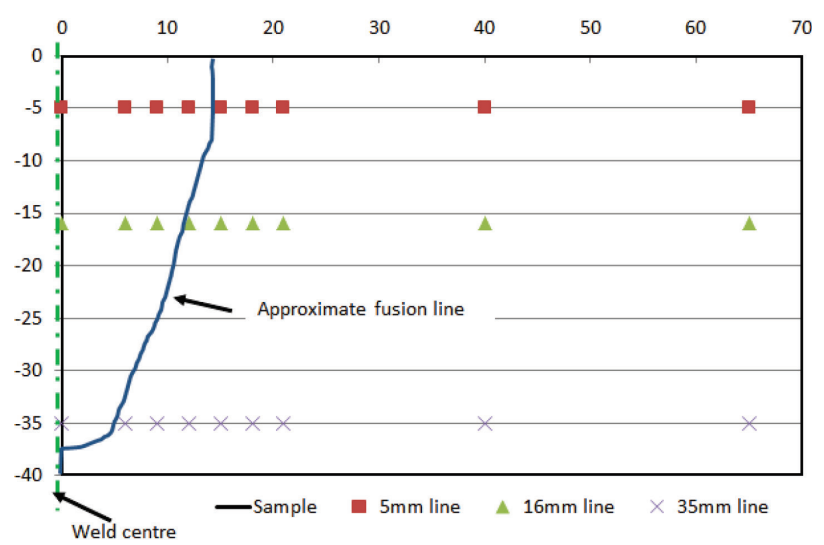

Fig. 5: Matrix of measurement points.

Through this experimental work the residual strains in four coupons in three directions (hoop, axial and radial) were determined.

\section{Table 2: Test coupon welded and-heat treated conditions}

\begin{tabular}{ll} 
Sample Number & Description \\
\hline 1A & Butt weld with Ni-based austenitic consumables without PWHT (As- \\
welded) \\
1B & Butt weld with Ni-based austenitic consumables with PWHT \\
2A & Butt weld with ferritic consumables without PWHT (As-welded) \\
2B & Butt weld with ferritic consumables with PWHT \\
$\mathrm{d}_{\text {zero }}$ cubes & $2 \times 2 \times 2 \mathrm{~mm}^{3}$ cubes across weld zone for unstrained lattice parameter \\
& determination
\end{tabular}

Residual stresses were inferred from standard strain-to-stress formulae by assuming that the measured strain values were in the three principal directions and using an elastic modulus (E) of 212.7 GPa and a Poisson's ratio (v) of 0.28 . The reference lattice parameter $\mathrm{d}_{\text {zero }}$ was measured on cubes $2 \times 2 \times 2 \mathrm{~mm}^{3}$ extracted from sectioned weld coupons. The data obtained provide critical information relevant to the structural integrity of weld repaired $\mathrm{Cr}-\mathrm{Mo}-\mathrm{V}$ creep resistant materials and can be compared with FE modelling predictions. The SALSA instrument offers the ability to efficiently characterise stresses in weldments of $36 \mathrm{~mm}$ thickness at high spatial resolution. Radial collimators were used that provided a gauge volume of $0.6 \times 0.6 \times 2 \mathrm{~mm}^{3}$ in conjunction with a neutron beam wavelength of $\lambda=1.644 \AA$.

\section{Results and discussion}

Notable results of the measurements are shown in the following figures: 
- Fig. 6, comparison of as-welded and heat-treated data on the $16 \mathrm{~mm}$ line for samples $1 \mathrm{~A}$ and $1 \mathrm{~B}$

- Fig. 7, comparison of as-welded and heat-treated data on the $16 \mathrm{~mm}$ line for samples $2 \mathrm{~A}$ and $2 \mathrm{~B}$

- Figs. 8 and 9, surface contour plots extrapolated from the line scans on sample 2A.

Error bars have been omitted from Figs. 6 and 7 for clarity, but were in the order of $\pm 50 \mu \mathrm{m} / \mathrm{m}$ in the ferritic material and $\pm 110 \mu \mathrm{m} / \mathrm{m}$ in the austenitic material. The errors improved in the heat treated samples

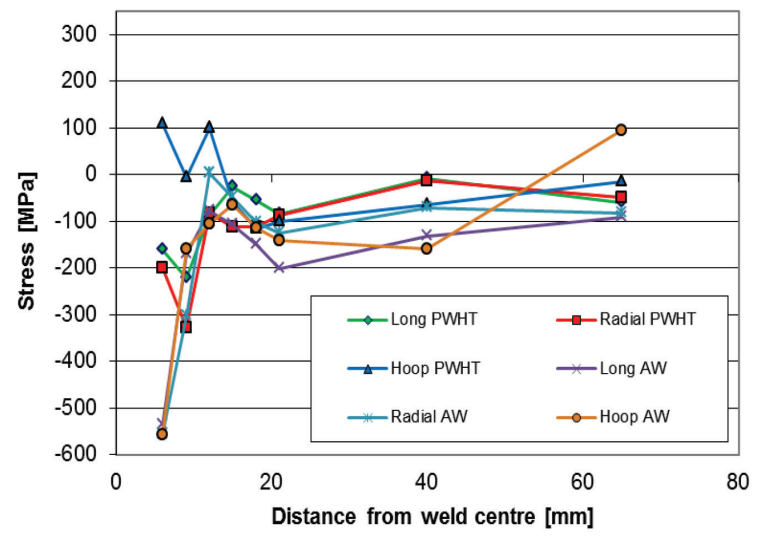

Fig. 6: Stress profiles $16 \mathrm{~mm}$ into sample, comparing 1A [As-welded] with $1 B$ [Heat treated].

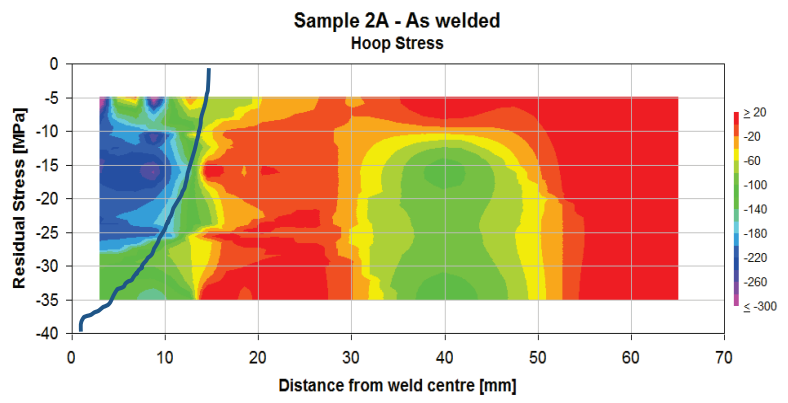

Fig. 8: Sample 2A - Extrapolated contour plot of hoop stress.

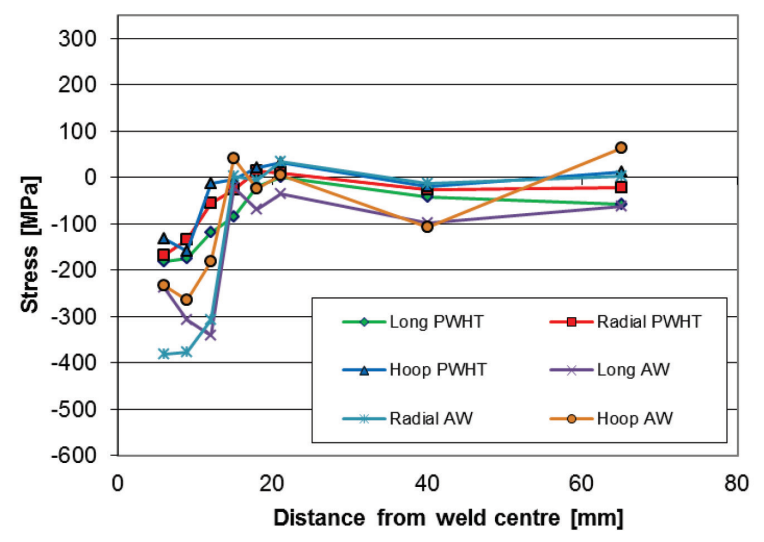

Fig. 7: Stress profiles $16 \mathrm{~mm}$ into sample, comparing $2 A$ [As-welded] with $2 B$ [heat treated].

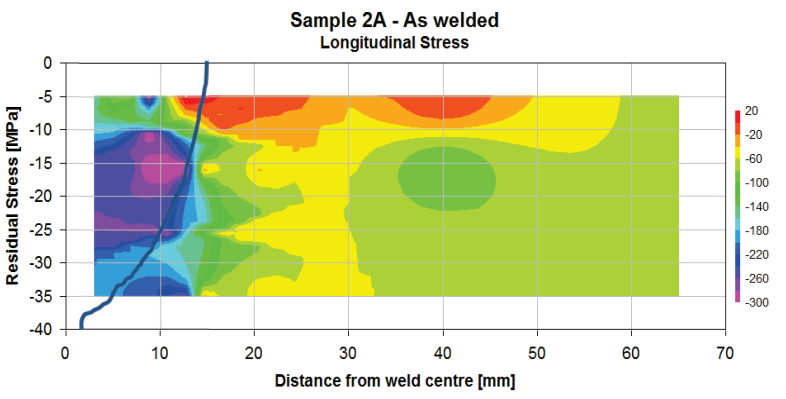

Fig. 9: Sample 2A - Extrapolated contour plot of longitudinal stress.

The experimental data for the as-welded condition of the austenitic weld metal on a ferritic base revealed a peak compressive stress exceeding the yield point of the Grade 14MoV6-3 base material in the vicinity of the HAZ. PWHT dramatically reduces this to a more gentle compressive residual stress gradient across the HAZ, the hoop stress appears to invert to a tensile value. The stress measurements on the ferritic weld consumable sample in the as-welded condition revealed a reduced residual compressive stress field compared to the sample welded with austenitic weld consumables. Predictably, PWHT reduced this to a lower compressive stress value. A comparison of the ferritic and austenitic consumable welds in the as-welded condition shows a significant difference in peak compressive levels. PWHT reduces this difference and it 
can be assumed that the peak compressive stress fields for the two consumable types are the same for all practical purposes.

The results of the experiment clearly demonstrated the beneficial influence of PWHT by reducing the residual stress state of the completed welds for both ferritic and austenitic weld metal. From a weld residual stress point of view no conclusive evidence were found after analysis of the experimental data that can be construed as sufficient proof that austenitic weld consumables deposited on ferritic base material has significant metallurgical and mechanical benefits over ferritic weld consumables. However, the experimental methods applied here will however not be able to demonstrate the possible plant operational benefits that can be achieved during the weld thermal cycle when applying austenitic weld consumables to ferritic base materials.

\section{Conclusions}

- The benefit of heat treatment is clearly illustrated by the neutron diffraction tests

- The nickel-based consumable has higher as-welded stresses compared to the Fe filler

- No conclusive evidence could be found to prove that austenitic weld consumables deposited on ferritic base material has significant metallurgical and mechanical benefits over ferritic weld consumables

- The results of this study will support Eskom's life extension programme and the refurbishment of creep exhausted components

\section{References}

[1] C. Lundin and K. Khan, Fundamental Studies of the Metallurgical Causes and Mitigation of Reheat Cracking in 1 1/4Cr-1/2Mo and 21/4Cr-1Mo Steels. WRC Bulletin 409, February (1996)

[2] H. Schüller, L. Hagn and A. Woitscheck, Risse im Schweissnahtbereich von Formstücken aus Heissdampfleitungen, Werkstoffuntersuchungen; Der Maschieneschaden 47(1) (1974) 1-13.

[3] S. Brett, Type IIIa cracking in $1 / 2 \mathrm{CrMoV}$ steam pipework systems, Sci. Technol. Weld. Joining 9(1) (2004) 41-45.

[4] C. Meitzner, Stress relief cracking in Steel Weldments. WRC Bulletin (1975)

[5] D. Nerger, R. Blume and H. Schinkel, Weld reconditioning of a 14MoV 63 Hot Reheat Line with Nickel-Based Filler Metals without Subsequent Heat Treatment. VGB Kraftwerktechnik 74(10) (1994) 751-756. 